\title{
Molecular detection of Hepatozoon felis in cats from Maio Island, Republic of Cape Verde and global distribution of feline hepatozoonosis
}

\author{
Cristina Pereira', João Pedro Maia ${ }^{2,3}$, Ricardo Marcos ${ }^{1}$, Camilla Luzzago ${ }^{4,5}$, Pablo Puente-Payo ${ }^{1}$, Paola Dall'Ara ${ }^{4}$,
} Augusto Faustino ${ }^{1}$ and Stefania Lauzi ${ }^{4,6^{*}}$

\begin{abstract}
Background: Vector-borne diseases are emerging worldwide and have an important zoonotic relevance. In the last few years, the interest in vector-borne pathogens in cats has increased. However, studies on feline vector-borne pathogens on tropical islands are lacking. Islands differ from continental countries because they have an enclosed population of animals, with all year presence of the vectors and, most often, without vector control measures. This study focused on the molecular identification and phylogenetic analysis of vector-borne pathogens in autochthonous cats with a mixed indoor-outdoor lifestyle from Maio Island, Cape Verde archipelago.
\end{abstract}

Methods: Blood samples were collected from 80 asymptomatic cats, representing almost a quarter of the total cat population of the island. The presence of DNA of protozoa of the genus Hepatozoon and bacteria belonging to family Anaplasmataceae and to genus Bartonella was assessed by PCR and phylogenetic analysis was conducted. Statistical analysis was performed to identify risk factors associated with infection. For feline hepatozoonosis, a worldwide dataset of Hepatozoon felis sequences retrieved from mammal species and vectors along with Hepatozoon spp. sequences retrieved from felids was generated, phylogenetically analyzed and the geographical and host distribution was assessed.

Results: Hepatozoon felis genotype I was identified in 12 (15\%) cats from Maio Island whereas none of the cats were PCR positive for the other pathogens tested. No significant association of $\mathrm{H}$. felis infection with age, sex, location or presence of vectors was observed by statistical analysis in Cape Verde's cats. Phylogenetic analysis on the worldwide dataset of feline Hepatozoon sequences showed two significant distinct clades for $\mathrm{H}$. felis genotype I and II. Different geographical distributions were assessed: H. felis genotype I was the only genotype found in Africa and has been reported worldwide, with the exception of Japan and Brazil where only H. felis genotype II has been reported.

Conclusions: The identification of $H$. felis genotype I in cats in Maio Island highlights the need to further investigate the significance of $H$. felis genotypes and to clarify the epidemiological aspects of this infection.

Keywords: Vector-borne pathogens, Anaplasmosis, Ehrlichiosis, Bartonellosis, Phylogeny, Felid

\footnotetext{
*Correspondence: stefania.lauzi@unimi.it

${ }^{4}$ Department of Veterinary Medicine, University of Milan, Via Celoria 10,

20133 Milan, Italy

Full list of author information is available at the end of the article
} 


\section{Background}

Vector-borne pathogens (VBPs) are recognized as agents causing important emerging diseases worldwide in humans and animals and represent an increasing concern for their zoonotic potential [1]. It is widely recognized that companion animals, especially dogs, play an important role in the epidemiology of vector-borne diseases (VBDs) acting as reservoirs and/or sentinels for several human and/or animal VBDs [2].

Numerous studies have been performed on canine VBDs, whereas feline vector-borne infections have been much less investigated, despite cats being ubiquitous companion animals [3]. Previous publications showed that although cats often have an outdoor lifestyle with a high risk of exposure to arthropods and are susceptible to tick bites and tick-borne agents, they appear to be less affected by tick-borne pathogens compared to dogs in geographical areas endemic for VBDs [2, 4]. This may be attributed to peculiar habits and behavior (e.g. grooming) of cats or to natural resistance to these pathogens or their vectors $[2,4]$. Furthermore, the relatively limited knowledge about feline VBDs probably reflects a lack of awareness of these pathogens in cats in endemic areas, likely due to the disease manifesting subclinically in most of the infected cats [5]. Therefore, the control of vectors and VBDs in cats is nowadays considered highly relevant [6].

In the last few years, studies on feline VBPs have shown a wide geographical distribution of these pathogens, especially in areas with endemic VBDs in dogs [7-11]. Vector-borne diseases have also been reported in cats living in confined environments, such as small islands [5].

Among pathogens potentially transmitted by ticks in cats, feline hepatozoonosis has been increasingly reported in cats and wild felids and two $H$. felis genotypes have been identified [12]. The exact vectors and routes of transmission of feline hepatozoonosis are not known but transmission by vectors likely plays a key role as for other species of Hepatozoon [13].

Vector-borne pathogens transmitted or potentially transmitted by Rhipicephalus sanguineus (sensu lato), some of them being zoonotic, have been reported in dogs from Santiago and Maio islands of the Archipelago of Cape Verde $[14,15]$. To date, Rh. sanguineus (s.l.) is the only hard tick that has been reported in the Cape Verde archipelago and it has been observed all year long. Moreover, Ctneocephalides felis has been reported among the four more common species of fleas that occur in the Cape Verde archipelago [16]. Although cats in the Cape Verde archipelago may be at risk of VBPs, and because vector control measures are not routinely applied to cats, studies on feline VBPs are lacking in this archipelago. To the best of our knowledge, the only study on feline VBPs in the Cape Verde archipelago was limited to an investigation of the presence of Dirofilaria, but this pathogen was not identified in cats [17].

A population of 354 cats has been estimated in Maio Island with most cats being privately owned [18]. Considering that tick-borne pathogens have been previously reported in dogs in Cape Verde, the aims of this study were thus to (i) apply microscopical and molecular detection methods to investigate the occurrence of agents of bacteria family Anaplasmataceae and genus Bartonella, as well as the protozoan genus Hepatozoon, in a representative sample size of cats from Maio Island; (ii) assess the phylogenetic relationships among feline pathogens detected in Maio island and feline Hepatozoon sequences reported worldwide, analyzing host and geographical distribution; and (iii) identify risk factors associated with infection in cats from Maio Island.

\section{Methods}

\section{Animals and sample collection}

A representative sample size of 80 animals was calculated using WinEpi (http://www.winepi.net) for the detection of pathogens in the cat population, considering the minimum prevalence of tick-borne pathogens (3.5\%) detected in the dog population of Maio Island [15]. Cats were included in the study using a non-probabilistic sampling method. Criteria for inclusion were the owner's consent, autochthonous origin of animals and age $\geq 6$ months. All cats were apparently healthy, but detailed clinical examinations were not conducted. The cats lived indoors with variable access to the outdoors and were considered to have a mixed indoor-outdoor lifestyle. Although climatic conditions of Maio Island allow a potential exposure to vectors all year long, owners were not aware of VBPs and no vector control measures had been used in these cats. Animals were sampled during November of 2012 throughout the island and data on age, sex, locality and presence of ticks or fleas were recorded for each cat.

Two milliliters of blood were collected by jugular venipuncture from each cat. Blood was kept in ethylene diamine tetraacetic acid (EDTA) tubes at $4{ }^{\circ} \mathrm{C}$ until further processing (up to $12 \mathrm{~h}$ ). For each animal, four separate $50 \mu \mathrm{l}$ dots of blood were spotted onto Whatman ${ }^{\circledR}$ filter paper, dried completely, and stored at $4{ }^{\circ} \mathrm{C}$ in order to be used later for molecular analysis.

\section{Microscopical screening}

A buffy coat smear (BCS) was performed for each animal, as detailed elsewhere [19]. Buffy coat smears were stained with a Diff-Quik (Hemacolor, Merck, Darmstadt, Germany) and screened using a microscope (Olympus CX31, Olympus, Tokyo, Japan) at $100 \times$ magnification for the presence of blood gamonts or morulae infecting neutrophils, monocytes or platelets. 
Molecular and phylogenetic analysis

DNA was extracted from Whatman ${ }^{\circledR}$ papers using a commercial kit, following the manufacturer's instructions (NucleoSpin Tissue, Macherey-Nagel, Düren, Germany).

Specific published PCR protocols were used to detect DNA of bacteria of the family Anaplasmataceae [20], genus Bartonella [21] and protozoa of the genus Hepatozoon [22]. DNA extracted from Anaplasma phagocytophilum and Hepatozoon canis infected dogs and from Bartonella henselae infected cats were used as positive controls in PCR reactions. A blank control (water sample) was also included in all PCR reactions. Gel-electrophoresis was conducted using $2 \%$ agarose gels.

For Hepatozoon spp., the positive samples with a PCR product of $631 \mathrm{bp}$ were purified and sequenced using the forward and reverse primers used for DNA amplification [22]. Sequencing was performed using a commercial sequencing facility (Macrogen Inc., Seoul, South Korea). The sequence data were assembled, and manual editing was performed using BioEdit software v.7.0 (freely available at http://www.mbio.ncsu.edu/BioEdit/bioedit.html) and Geneious v.6.1 (Biomatters Ltd., Auckland, New Zealand). The sequences were then compared with those available in GenBank using BLAST (http://blast.ncbi. nlm.nih.gov/Blast.cgi).

Sequences from Cape Verde cats were aligned with representative $H$. felis genotype I, $H$. felis genotype II, $H$. canis, $H$. americanum, $H$. silvestris, $H$. martis sequences retrieved from GenBank, using Clustal X in BioEdit software v.7.0. Phylogeny was estimated by a neighborjoining algorithm (NJ) [23] and by maximum likelihood (ML) [24] methods with 1000 bootstrap replicates using MEGA v.7 [25].

The representative $H$. felis sequence obtained in this study was deposited in GenBank under accession number MK836092.

\section{Host and geographical distribution of feline Hepatozoon sequences reported worldwide}

A dataset of 269 feline Hepatozoon sequences retrieved from GenBank was generated. Sequences were retrieved from peer-reviewed journals $[5,7,12,13,26-60]$ or were publicly available from GenBank (accessed on 18 February 2019). Selection criteria for feline Hepatozoon sequences were identification in GenBank as Hepatozoon felis (retrieved from mammals and vectors) and Hepatozoon spp. sequences reported worldwide in domestic and wild felids (Additional file 1: Table S1). All the feline Hepatozoon sequences included in our dataset were phylogenetically analyzed as described above for sequences from cats of Maio Island. Phylogenetic analysis was performed to identify the genotype of $\mathrm{H}$. felis for the sequences deposited in GenBank that had not previously been assigned to a genotype.

According to the results of the phylogenetic analysis on the comprehensive dataset of feline Hepatozoon sequences and the representative $H$. felis sequence from Maio Island cats, the host and geographical distribution were assessed for each $H$. felis genotype and for other Hepatozoon species identified in felids.

\section{Statistical data analysis}

In the presence of negative results for the pathogens tested, the maximum possible prevalence in the total cat population was calculated using WinEpi (http://www. winepi.net).

Pearson's Chi-square test was used to evaluate the differences between proportions of infected cats and sex, age, village of origin, presence of ticks and presence of fleas. Statistical comparisons were carried out using SPSS v.15.0 software, taking $P<0.05$ as significant.

\section{Results}

The 80 cats of private owners that were analyzed in this study represented almost a quarter of the feline population in Maio Island [18]. Data collected regarding epidemiological information are shown in Table 1.

No circulating gamonts or morulae were detected by microscopic screening on BCS. Based on molecular analysis, 12 cats (15.0\%; 95\% CI: 7.2-22.8\%) were positive by PCR for the presence of Hepatozoon spp. All 12 sequences obtained from the PCR positive cats were identical and $H$. felis was identified by BLAST analysis showing $100 \%$ nucleotide identity with $H$. felis sequences from Spanish cats available in GenBank (accession numbers AY628681 and AY620232).

Phylogeny showed that $H$. felis sequence found in cats from Cape Verde clustered with $H$. felis sequences previously reported as $H$. felis genotype I, in a separate cluster from the $H$. felis genotype II sequences (Fig. 1) [12]. Similar results were obtained using the NJ and the ML methods.

Almost all (264/269) feline Hepatozoon sequences retrieved from GenBank and included in our comprehensive dataset clustered with previously reported Hepatozoon species and $H$. felis genotypes with a high phylogenetic support. The only exceptions were 5 feline Hepatozoon spp. sequences retrieved from domestic and wild felids in Brazil and from bobcats in the USA, that clustered separately from the $H$. felis genotypes I and II and from selected $H$. canis, $H$. silvestris, $H$. americanum and $H$. martis sequences (Fig. 1; detailed results are reported in Additional file 1: Table S1).

The geographical distribution and host species of all feline Hepatozoon sequences from the comprehensive 
Table 1 Comparison of prevalence of H. felis in cats from Maio Island in association with different epidemiological data

\begin{tabular}{|c|c|c|}
\hline Variable & No. of cats & $\begin{array}{l}\text { No. of H. felis- } \\
\text { positive cats } \\
\text { (\%) }\end{array}$ \\
\hline \multicolumn{3}{|l|}{ Age } \\
\hline Kitten ( $\geq 6$ months to $<1$ year-old) & 24 & $6(25.0)$ \\
\hline Adult ( $\geq 1$ year-old) & 56 & $6(10.7)$ \\
\hline \multicolumn{3}{|l|}{ Sex } \\
\hline Male & 42 & $9(28.1)$ \\
\hline Female & 38 & $3(7.9)$ \\
\hline \multicolumn{3}{|l|}{ Village of origin } \\
\hline Morro & 5 & - \\
\hline Calheta & 20 & $4(20.0)$ \\
\hline Praia Gonçalo & 3 & $1(33.3)$ \\
\hline Pedro Vaz & 6 & $1(16.7)$ \\
\hline Alcatraz & 5 & - \\
\hline Pilão Cão & 1 & - \\
\hline Ribeira D. João & 8 & - \\
\hline Figueira da Horta & 4 & - \\
\hline Barreiro & 10 & $1(10.0)$ \\
\hline Cidade do Porto Inglês & 18 & $5(27.8)$ \\
\hline \multicolumn{3}{|l|}{ Presence of ticks } \\
\hline Yes & 4 & $2(50.0)$ \\
\hline No & 76 & $10(13.2)$ \\
\hline \multicolumn{3}{|l|}{ Presence of fleas } \\
\hline Yes & 24 & $5(20.8)$ \\
\hline No & 56 & $7(12.5)$ \\
\hline
\end{tabular}

dataset comprising $H$. felis genotype I and genotype II identified in the phylogenetic analysis and the representative sequence of $H$. felis genotype I from Cape Verde cats are reported in Table 2 (detailed results are reported in Additional file 1: Table S1).

DNA from bacteria of the family Anaplasmataceae and the genus Bartonella was not detected in our survey. A $3.4 \%$ maximum possible prevalence in the total cat population of Maio Island of approximately 350 animals [18] was calculated for these pathogens with negative PCR results in all the samples tested.

No statistically significant differences were found between the prevalence of $H$. felis infection and the variables tested (Table 1).

\section{Discussion}

To our knowledge, this is the first survey on feline VBPs in the Cape Verde archipelago, comprising small tropical islands with a confined and stable population of animals, with all year long presence of the vectors. Our results show that $H$. felis was present in the cat population of Maio Island.
The detection of $H$. felis by molecular techniques but not by microscopy on blood smears confirms that diagnosis of $H$. felis infection in blood samples should rely on the PCR technique. This is because microscopy of blood smears is not sensitive enough for the detection of Hepatozoon gamonts, due to the limited level of parasitemia, with less than $1 \%$ of neutrophils and monocytes containing gamonts [61-63]. In our study, the use of BCS, previously reported in dogs as providing an increase in sensitivity over direct blood smears in $\mathrm{H}$. canis detection [64], did not improve diagnostic performance, further confirming that microscopy is not suitable for Hepatozoon diagnosis in feline blood samples.

The finding of $\mathrm{H}$. felis as the unique species of Hepatozoon infecting domestic cats in Maio Island is in agreement with previous observations on $H$. felis being the most frequent Hepatozoon species reported in cats, especially in geographical areas with endemic infection [13]. Indeed, despite the presence of $H$. canis in dogs in Maio Island [15], only $H$. felis was found in cats from this island.

Among the variable prevalence estimations for $\mathrm{H}$. felis that have been found in cats in different countries [5, $7,38,42,61]$, the $15 \%$ prevalence of $\mathrm{H}$. felis reported in Maio Island resembles that reported in domestic cats in Barcelona, Spain (16\%) [65] and in Portugal (16\%) [11].

The identification by phylogenetic analysis of $H$. felis genotype I in cats from Maio Island was not surprising, as this is the most frequent $H$. felis genotype reported in cats $[5,12,13,32,38,41,48]$. The presence of the $H$. felis genotype I cluster distinct from the $H$. felis genotype II cluster is in agreement with previous studies [12]. The two strongly supported distinct clades for $\mathrm{H}$. felis genoype I and genotype II also suggest that they probably represent two different Hepatozoon species. Therefore, only one $\mathrm{H}$. felis genotype may be referred to as $\mathrm{H}$. felis while the other may be indicative of a different Hepatozoon species, as recently proposed [5].

Despite the wide geographical distribution of both $H$. felis genotypes, geographical differences between the $H$. felis genotype I and II were observed, as recently suggested [30]. Analysis on feline Hepatozoon sequences retrieved from GenBank showed that $H$. felis genotype I was the only genotype identified in Africa and the Middle East and was also the most frequent genotype observed in the Mediterranean basin. On the other hand, H. felis genotype II was the only $H$. felis genotype found in Brazil and Japan, as previously reported [37, 42, 49, 56-58].

Our analysis assessed the absence of host specificity for feline Hepatozoon species, confirming that these parasites are not considered to be specific of the suborders (felids and canids) of Carnivora [13, 59]. Indeed, both genotypes of $\mathrm{H}$. felis were previously reported in 


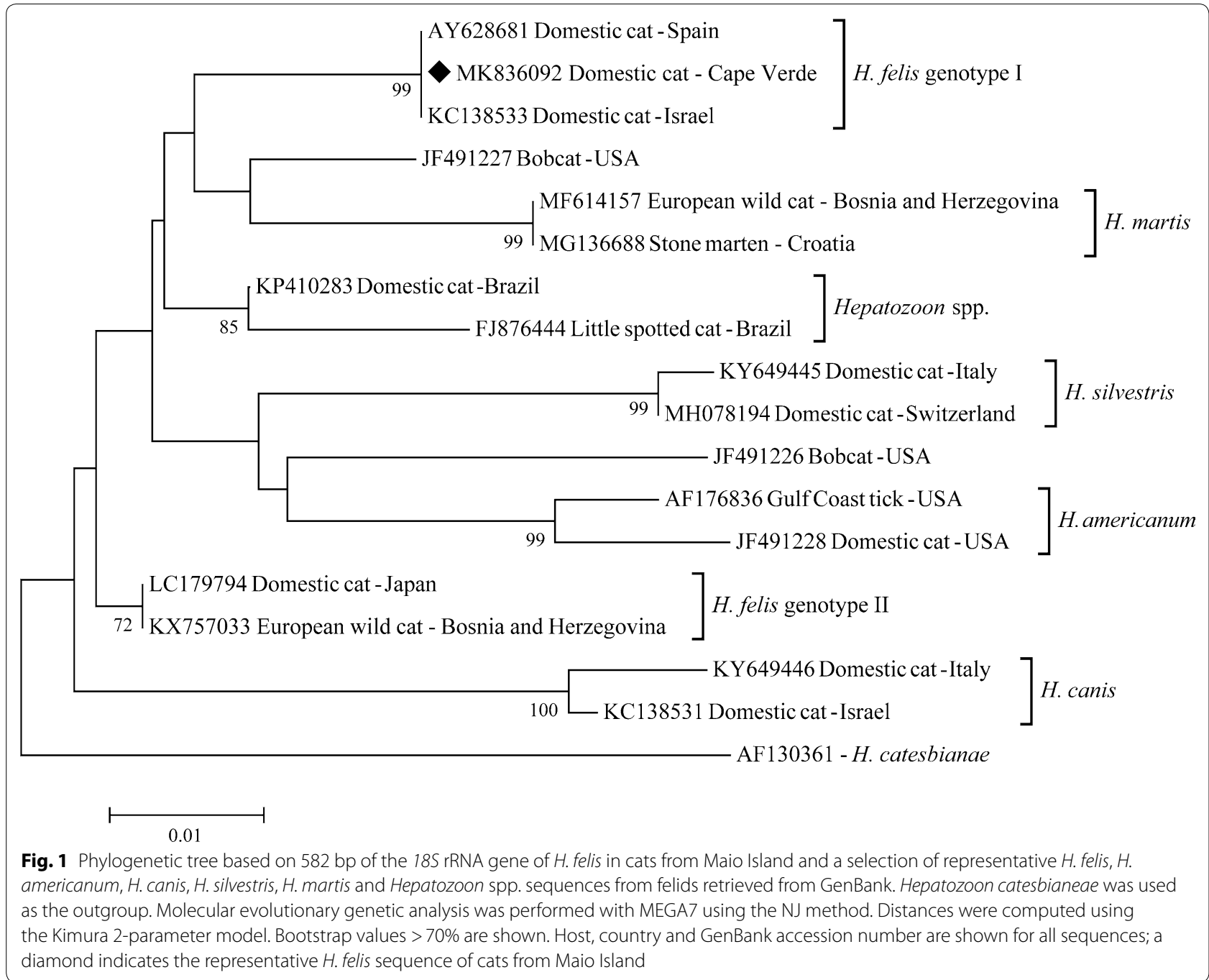

domestic and wild felids and $H$. felis genotype I was also reported in other mammals (foxes, rodents, hyenas) [39, $43,50,59]$. Our phylogenetic study also showed that felids can be infected by Hepatozoon species typically observed in dogs (H. canis, H. americanum) or in martens (H. martis), as previously reported $[28,33,61,66]$. Moreover, domestic cats can also be infected by $H$. silvestris previously reported only in wild felids [38, 40, 41, 45]. However, in Maio Island only H. felis was detected in our study. Further studies are needed to understand the differences between the $H$. felis genotypes and more generally the Hepatozoon spp. infecting felids in terms of their etiological and epidemiological significance.

A few risk factors have been identified to date for feline hepatozoonosis [61]. The previously reported association between infection and outdoor access, suggesting transmission by hematophagous arthropods or predation as demonstrated for other Hepatozoon spp. [13], could not be confirmed in our study because all privately-owned cats from Maio Island had a mixed indoor-outdoor lifestyle. Despite the fact that $R h$. sanguineus (s.l.) is the only hard tick present in the Cape Verde archipelago [16] and has been suggested as candidate vector of $H$. felis infection, resembling the well-established scenario of $H$. canis in dogs $[47,67]$, the association of $H$. felis infection in cats with presence of ticks was not found in our investigation. Further studies on cats and vectors are needed to confirm the route of transmission of $H$. felis infection in Maio Island. Our results showed that neither age nor sex was associated with $H$. felis infection in cats, confirming previous results [13]. The absence of a significant association between $\mathrm{H}$. felis infection in cats and location suggests that the infection was distributed on the whole island, probably reflecting animal movement or the wide distribution of ticks [16]. The presence of $H$. felis in apparently healthy cats from Maio Island was not surprising, since $H$. felis is commonly associated with subclinical symptoms [13]. 
Table 2 Geographical distribution and hosts for 248 sequences retrieved from GenBank and identified by phylogenetic analysis as $H$. felis genotype I and genotype II and the representative Hepatozoon sequence from Cape Verde cats

\begin{tabular}{|c|c|c|c|c|c|}
\hline Continent & Country & Host & $\begin{array}{l}\text { H. felis genotype } \\
\text { I (n) }\end{array}$ & $\begin{array}{l}\text { H. felis genotype } \\
\text { II (n) }\end{array}$ & References $^{\mathrm{a}}$ \\
\hline \multirow[t]{6}{*}{ Europe } & Bosnia and Herzegovina & European wild cat & 1 & 1 & {$[40,41]$} \\
\hline & Croatia & Tick & 1 & - & MH656727 \\
\hline & Italy & Domestic cat & 4 & - & {$[5,38]$} \\
\hline & Portugal & Domestic cat & 13 & - & {$[48]$} \\
\hline & & Tick & 4 & - & {$[47]$} \\
\hline & Spain & Domestic cat & 2 & - & {$[32]$} \\
\hline \multirow[t]{5}{*}{ Africa } & Angola & Domestic cat & 3 & - & {$[51]$} \\
\hline & Cape Verde & Domestic cat & 1 & - & This study \\
\hline & Nigeria & Rat & 2 & - & [43] \\
\hline & Zambia & Lion & 2 & - & [59] \\
\hline & & Spotted hyena & 1 & - & {$[59]$} \\
\hline \multirow[t]{16}{*}{ Asia } & Cyprus & Domestic cat & 28 & - & [7]; KX808658- KX808671 \\
\hline & Israel & Domestic cat & 5 & - & [13] \\
\hline & & Flea & 4 & - & {$[60]$} \\
\hline & Turkey & Tick & 2 & 2 & {$[26,27,44]$} \\
\hline & India & Domestic cat & 2 & - & {$[12]$} \\
\hline & & Asiatic lion & 1 & 5 & {$[12] ; \mathrm{KX} 017290$} \\
\hline & & Bengal tiger & 2 & - & {$[12]$} \\
\hline & & Indian leopard & - & 2 & {$[12]$} \\
\hline & Thailand & Flat-headed cat & - & 1 & {$[54]$} \\
\hline & & Leopard cat & 1 & - & {$[55]$} \\
\hline & & Tick & 1 & - & {$[31]$} \\
\hline & Republic of Korea & Leopard cat & 1 & 2 & [46] \\
\hline & Japan & Domestic cat & - & 6 & {$[42]$} \\
\hline & & Amur leopard cat & - & 28 & {$[57]$} \\
\hline & & Iriomote cat & - & 52 & {$[53,57]$} \\
\hline & & Tick & - & 53 & [58] \\
\hline \multirow[t]{8}{*}{ South America } & Argentina & Pampas fox & 1 & - & {$[39]$} \\
\hline & & South American gray fox & 1 & - & {$[50]$} \\
\hline & & Tick & 1 & - & {$[50]$} \\
\hline & Brazil & Domestic cat & - & 2 & {$[30,37]$} \\
\hline & & Jaguar & - & 6 & {$[37]$} \\
\hline & & Little spotted cat & - & 2 & FJ876445-FJ876446 \\
\hline & & Neotropical felid & - & 2 & {$[49]$} \\
\hline & & Ocelot & - & 1 & [56] \\
\hline
\end{tabular}

${ }^{a}$ GenBank accession number is provided for otherwise unpublished sequences

Regarding the negative PCR results for the other VBPs tested in this study, it has to be taken into account that even if almost one quarter of the whole population of cats in Maio Island was studied, this sampling size is not adequate for drawing any definitive conclusion on absence or very low prevalence of these VBPs in the cat population.

Despite the fact that Ehrlichia canis and Anaplasma platys were previously reported in dogs from Maio Island, the negative PCR results in cats supports findings indicating that cats are less frequently affected by arthropod-borne pathogens than dogs, likely due to the lower rate of tick infestation generally reported in cats compared to dogs [2]. Indeed, in our study ticks were detected in only four (5\%) cats. The negative PCR result of Anaplasma phagocytophilum in cats is also in agreement with negative results in dogs of the same areas, as the vector Ixodes ricinus has not been reported in the archipelago $[15,16]$.

The negative PCR results for Bartonella spp. were not expected, since feline bartonellosis has been reported in 
cats worldwide and transmission in cats can occur by the cat flea (Ctenocephalides felis) [68]. Despite the fact that fleas were observed in 24 (30\%) cats from Maio Island, the calculated $3.4 \%$ maximum possible prevalence of feline bartonellosis is in agreement with low prevalence rates of $0.3,0.7,0.9$ and $2.9 \%$ that have been reported in Spain, Albania, Algeria and Portugal, respectively $[8,48$, $69,70]$.

\section{Conclusions}

To our knowledge, this is the first time that infection with $H$. felis has been reported in the Cape Verde archipelago in cats; $H$. felis genotype I was observed, reinforcing previous findings that, to date, only this genotype has been reported in Africa. The presence of H. felis in Maio Island should encourage a campaign of VBPs monitoring in the Cape Verde archipelago, with special emphasis on the investigation in animals and vectors, possible routes of infection and impact of infection in cats, especially to obtain a wider perspective on feline hepatozoonosis.

\section{Additional file}

Additional file 1: Table S1. Data on feline Hepatozoon sequences: Hepatozoon species classification based on results of phylogenetic analysis of 269 selected $H$. felis sequences from mammal species and vectors, along with H. canis, H. silvestris and Hepatozoon spp. sequences from felids retrieved from GenBank and the representative Hepatozoon spp. sequence from Cape Verde cats.

\section{Abbreviations}

PCR: polymerase chain reaction; VBDs: vector-borne diseases; BCS: buffy coat smear; NJ: neighbor-joining; ML: maximum likelihood.

\section{Acknowledgements}

We thank Lara Balloi for technical assistance.

\section{Authors' contributions}

CP conducted clinical examinations, collection of samples and revised the manuscript. JPM performed molecular analysis and revised the manuscript. RM conceived the study and conducted microscopical screening. CL helped in conceiving the study, contributed in phylogenetic analysis and revised the manuscript. PP-P conceived and designed the study and conducted collection of samples. PDA analyzed data and revised the manuscript. AF conceived the study and revised the manuscript. SL helped in conceiving the study, performed phylogeny and revised the manuscript. All authors read and approved the final manuscript.

\section{Funding}

This study was partially funded by University of Milan, Italy (Piano Sviluppo UNIMI 2014, PI Lauzi) and Fundação para a Ciência e a Tecnologia (FCT) doctoral fellowship under the Programa Operacional Potencial Humano, Quadro de Referência Estratégico Nacional funds (POPH-QREN) from the European Social Fund (ESF) and Portuguese Ministério da Educação e Ciência (SFRH/ BD/74305/2010, JPM).

\section{Availability of data and materials}

All datasets supporting the conclusions of this article are included within the article and its additional file. Raw data are available from the corresponding author upon request. A representative sequence was submitted to the GenBank database under the accession number MK836092.

\section{Ethics approval and consent to participate}

All owners of cats gave informed consent to participate in the study.

\section{Consent for publication}

Not applicable.

\section{Competing interests}

The authors declare that they have no competing interests.

\section{Author details}

${ }^{1}$ Institute of Biomedical Sciences Abel Salazar, University of Porto, Porto, Portugal. ${ }^{2} \mathrm{CIBIO}$ Research Centre in Biodiversity and Genetic Resources, InBIO, Universidade do Porto, Campus Agrário de Vairão, Rua Padre Armando Quintas, № 7, Vila do Conde, 4485-661 Vairão, Portugal. ${ }^{3}$ Departamento de Biologia, Faculdade de Ciências, Universidade do Porto, Rua do Campo Alegre FC4, 4169-007 Porto, Portugal. ${ }^{4}$ Department of Veterinary Medicine, University of Milan, Via Celoria 10, 20133 Milan, Italy. ${ }^{5}$ Coordinated Research Center "EpiSoMI", University of Milan, Milan, Italy. ${ }^{6}$ Veterinary Teaching Hospital, University of Milan, Lodi, Italy.

Received: 20 March 2019 Accepted: 3 June 2019

Published online: 11 June 2019

\section{References}

1. Dantas-Torres F, Chomel BB, Otranto D. Ticks and tick-borne diseases: a one health perspective. Trends Parasitol. 2012;28:437-46.

2. Day MJ. Cats are not small dogs: is there an immunological explanation for why cats are less affected by arthropod-borne disease than dogs? Parasit Vectors. 2016;9:507.

3. Chomel BB, Sun B. Zoonoses in the bedroom. Emerg Infect Dis. 2011;17:167-72.

4. Shaw SE, Birtles RJ, Day MJ. Arthropod-transmitted infectious diseases of cats. J Feline Med Surg. 2001;3:193-209.

5. Otranto D, Napoli E, Latrofa MS, Annoscia G, Tarallo VD, Greco G, et al. Feline and canine leishmaniosis and other vector-borne diseases in the Aeolian Islands: pathogen and vector circulation in a confined environment. Vet Parasitol. 2017;236:144-51.

6. Otranto D, Dantas-Torres F, Napoli E, Solari Basano F, Deuster K, Pollmeier $\mathrm{M}$, et al. Season-long control of flea and tick infestations in a population of cats in the Aeolian archipelago using a collar containing 10\% imidacloprid and 4.5\% flumethrin. Vet Parasitol. 2017:248:80-3.

7. Attipa C, Papasouliotis K, Solano-Gallego L, Baneth G, Nachum-Biala Y, Sarvani E, et al. Prevalence study and risk factor analysis of selected bacterial, protozoal and viral, including vector-borne, pathogens in cats from Cyprus. Parasit Vectors. 2017;10:130.

8. Ayllón T, Diniz PP, Breitschwerdt EB, Villaescusa A, Rodríguez-Franco $F$, Sainz A. Vector-borne diseases in client-owned and stray cats from Madrid, Spain. Vector Borne Zoonotic Dis. 2012;12:143-50.

9. Díaz-Regañón D, Villaescusa A, Ayllón T, Rodríguez-Franco F, Baneth G, Calleja-Bueno L, et al. Molecular detection of Hepatozoon spp. and Cytauxzoon sp. in domestic and stray cats from Madrid, Spain. Parasit Vectors. 2017:10:112

10. Persichetti MF, Solano-Gallego L, Serrano L, Altet L, Reale S, Masucci M, et al. Detection of vector-borne pathogens in cats and their ectoparasites in southern Italy. Parasit Vectors. 2016;9:247.

11. Vilhena H, Martinez-Díaz VL, Cardoso L, Vieira L, Altet L, Francino O, et al. Feline vector-borne pathogens in the north and centre of Portugal. Parasit Vectors. 2013;6:99.

12. Pawar RM, Poornachandar A, Srinivas P, Rao KR, Lakshmikantan U, Shivaji S. Molecular characterization of Hepatozoon spp. infection in endangered Indian wild felids and canids. Vet Parasitol. 2012;186:475-9.

13. Baneth G, Sheiner A, Eyal O, Hahn S, Beaufils JP, Anug Y, Talmi-Frank D. Redescription of Hepatozoon felis (Apicomplexa: Hepatozoidae) based on phylogenetic analysis, tissue and blood form morphology, and possible transplacental transmission. Parasit Vectors. 2013;6:102. 
14. Götsch S, Leschnik M, Duscher G, Burgstaller JP, Wille-Piazzai W, Joachim A. Ticks and haemoparasites of dogs from Praia, Cape Verde. Vet Parasitol. 2009;166:171-4

15. Lauzi S, Maia JP, Epis S, Marcos R, Pereira C, Luzzago C, et al. Molecular detection of Anaplasma platys, Ehrlichia canis, Hepatozoon canis and Rickettsia monacensis in dogs from Maio Island of Cape Verde archipelago. Ticks Tick Borne Dis. 2016;7:964-9.

16. Duarte EH. The haematophagous arthropods (Animalia: Arthropoda) of the Cape Verde islands: a review. Zoologia Caboverdiana. 2013:4:31-42.

17. Marcos R, Pereira C, Maia JP, Santos M, Luzzago C, Lauzi S, et al. The occurrence of the filarial nematode Dirofilaria repens in canine hosts from Maio Island, Cape Verde. J Helminthol. 2017;91:87-90.

18. Lopes Antunes AC, Ducheyne E, Bryssinckx W, Vieira S, Malta M, Vaz Y, et al. The dog and cat population on Maio Island, Cape Verde: characterisation and prediction based on household survey and remotely sensed imagery. Geospat Health. 2015;10:386.

19. Marcos R, Pereira C, Santos M, Luzzago C, Lauzi S, Maia JP, et al. Buffy coat smear or Knott's test: which to choose for canine microfilaria screening in field studies? Vet Clin Pathol. 2016;45:201-5.

20. Parola P, Roux V, Camicas JL, Baradji I, Brouqui P, Raoult D. Detection of ehrlichiae in African ticks by polymerase chain reaction. Trans $\mathrm{R}$ Soc Trop Med Hyg. 2000;94:707-8.

21. Jensen WA, Fall MZ, Rooney J, Kordick DL, Breitschwerdt EB. Rapid identification and differentiation of Bartonella species using a single-step PCR assay. J Clin Microbiol. 2000;38:1717-22.

22. Ujvari B, Madsen T, Olsson M. High prevalence of Hepatozoon spp. (Apicomplexa: Hepatozoidae) infection in water pythons (Liasis fuscus) from tropical Australia. J Parasitol. 2004;90:670-2.

23. Kimura M. A simple method for estimating evolutionary rates of base substitutions through comparative studies of nucleotide sequences. J Mol Evol. 1980;16:111-20.

24. Felsenstein J. Evolutionary trees from DNA sequences: a maximum likelihood approach. J Mol Evol. 1981;17:368-76.

25. Kumar S, Stecher G, Tamura K. MEGA7: molecular evolutionary genetics analysis version 7.0 for bigger datasets. Mol Biol Evol. 2016;33:1870-4

26. Aktas M, Ozübek S, Ipek DN. Molecular investigations of Hepatozoon species in dogs and developmental stages of Rhipicephalus sanguineus. Parasitol Res. 2013;112:2381-5.

27. Aktas M. A survey of ixodid tick species and molecular identification of tick-borne pathogens. Vet Parasitol. 2014;200:276-83.

28. Allen KE, Yabsley MJ, Johnson EM, Reichard MV, Panciera RJ, Ewing SA, et al. Novel Hepatozoon in vertebrates from the southern United States. J Parasitol. 2011;97:648-53.

29. André MR, Herrera HM, Fernandes SJ, de Sousa KC, Gonçalves LR, Domingos $\mathrm{H}$, et al. Tick-borne agents in domesticated and stray cats from the city of Campo Grande, state of Mato Grosso do Sul, midwestern Brazil. Ticks Tick Borne Dis. 2015;6:779-86.

30. Braga ÍA, de Souza Ramos DG, Marcili A, Melo ALT, Taques IIGG, Amude $\mathrm{AM}$, et al. Molecular detection of tick-borne protozoan parasites in a population of domestic cats in midwestern Brazil. Ticks Tick Borne Dis. 2016:7:1004-9.

31. Bhusri B, Sariya L, Mongkolphan C, Suksai P, Kaewchot S, Changbunjong T. Molecular characterization of Hepatozoon felis in Rhipicephalus sanguineus ticks infested on captive lions (Panthera leo). J Parasit Dis. 2017:41:903-7.

32. Criado-Fornelio A, Ruas JL, Casado N, Farias NA, Soares MP, Müller G, et al. New molecular data on mammalian Hepatozoon species (Apicomplexa: Adeleorina) from Brazil and Spain. J Parasitol. 2006:92:93-9.

33. Criado-Fornelio A, Buling A, Pingret JL, Etievant M, Boucraut-Baralon C, Alongi $A$, et al. Hemoprotozoa of domestic animals in France: prevalence and molecular characterization. Vet Parasitol. 2009;159:73-6.

34. de Bortoli CP, André MR, Braga Mdo S, Machado RZ. Molecular characterization of Hepatozoon sp. in cats from São Luís Island, Maranhão, Northeastern Brazil. Parasitol Res. 2011;109:1189-92.

35. de Sousa KC, Fernandes MP, Herrera HM, Benevenute JL, Santos FM, Rocha FL, et al. Molecular detection of Hepatozoon spp. in domestic dogs and wild mammals in southern Pantanal, Brazil with implications in the transmission route. Vet Parasitol. 2017;237:37-46.

36. East ML, Wibbelt G, Lieckfeldt D, Ludwig A, Goller K, Wilhelm K, et al. A Hepatozoon species genetically distinct from $\mathrm{H}$. canis infecting spotted hyenas in the Serengeti ecosystem, Tanzania. J Wildl Dis. 2008;44:45-52.
37. Furtado MM, Metzger B, de Almeida Jácomo AT, Labruna MB, Martins TF, O'Dwyer LH, et al. Hepatozoon spp. infect free-ranging jaguars (Panthera onca) in Brazil. J Parasitol. 2017:103:243-50.

38. Giannelli A, Latrofa MS, Nachum-Biala Y, Hodžić A, Greco G, Attanasi A, et al. Three different Hepatozoon species in domestic cats from southern Italy. Ticks Tick Borne Dis. 2017;8:721-4.

39. Giannitti F, Diab SS, Uzal FA, Fresneda K, Rossi D, Talmi-Frank D, et al. Infection with a Hepatozoon sp closely related to Hepatozoon felis in a wild Pampas gray fox (Lycalopex-Pseudalopex-gymnocercus) co-infected with canine distemper virus. Vet Parasitol. 2012;186:497-502.

40. Hodžić A, Alić A, Prašović S, Otranto D, Baneth G, Duscher GG. Hepatozoon silvestris sp. nov.: morphological and molecular characterization of a new species of Hepatozoon (Adeleorina: Hepatozoidae) from the European wild cat (Felis silvestris silvestris). Parasitology. 2016;144:650-61.

41. Hodžić A, Alić A, Duscher GG. High diversity of blood-associated parasites and bacteria in European wild cats in Bosnia and Herzegovina: a molecular study. Ticks Tick Borne Dis. 2018;9:589-93.

42. Jikuya M, Tateno M, Takahashi M, Endo Y. The presence of tick-borne diseases in domestic dogs and cats living on Iriomote-jima and Tsushima islands. J Vet Med Sci. 2017;79:1086-90.

43. Kamani J, Harrus S, Nachum-Biala Y, Gutiérrez R, Mumcuoglu KY, Baneth G. Prevalence of Hepatozoon and Sarcocystis spp. in rodents and their ectoparasites in Nigeria. Acta Trop. 2018;187:124-8.

44. Karasartova D, Gureser AS, Gokce T, Celebi B, Yapar D, Keskin A, et al. Bacterial and protozoal pathogens found in ticks collected from humans in Corum province of Turkey. PLoS Negl Trop Dis. 2018;12:e0006395.

45. Kegler K, Nufer U, Alic A, Posthaus H, Olias P, Basso W. Fatal infection with emerging apicomplexan parasite Hepatozoon silvestris in a domestic cat. Parasit Vectors. 2018;11:428.

46. Kubo M, Jeong A, Kim SI, Kim YJ, Lee H, Kimura J, et al. The first report of Hepatozoon species infection in leopard cats (Prionailurus bengalensis) in Korea. J Parasitol. 2010;96:437-9.

47. Maia C, Ferreira A, Nunes M, Vieira ML, Campino L, Cardoso L. Molecular detection of bacterial and parasitic pathogens in hard ticks from Portugal. Ticks Tick Borne Dis. 2014;5:409-14.

48. Maia C, Ramos C, Coimbra M, Bastos F, Martins A, Pinto P, et al. Bacterial and protozoal agents of feline vector-borne diseases in domestic and stray cats from southern Portugal. Parasit Vectors. 2014;7:115.

49. Metzger B, dos Santos Paduan K, Rubini AS, de Oliveira TG, Pereira C, O'Dwyer LH. The first report of Hepatozoon sp. (Apicomplexa: Hepatozoidae) in neotropical felids from Brazil. Vet Parasitol. 2008;152:28-33.

50. Millán J, Travaini A, Cevidanes A, Sacristán I, Rodríguez A. Assessing the natural circulation of canine vector-borne pathogens in foxes, ticks and fleas in protected areas of Argentine Patagonia with negligible dog participation. Int J Parasitol Parasites Wildl. 2018;8:63-70.

51. Oliveira AC, Luz MF, Granada S, Vilhena H, Nachum-Biala Y, Lopes AP, et al. Molecular detection of Anaplasma bovis, Ehrlichia canis and Hepatozoon felis in cats from Luanda, Angola. Parasit Vectors. 2018;11:167.

52. Rubini AS, Dos Santos Paduan K, Perez RR, Ribolla PE, O'D wyer LH. Molecular characterization of feline Hepatozoon species from Brazil. Vet Parasitol. 2006;137:168-71.

53. Sakuma M, Nishio T, Nakanishi N, Izawa M, Asari Y, Okamura M, et al. A case of Iriomote cat (Prionailurus bengalensis iriomotensis) with Hepatozoon felis parasitemia. J Vet Med Sci. 2011;73:1381-4.

54. Salakij C, Salakij J, Narkkong NA, Sirinarumitr T, Pattanarangsan R. Hematologic, cytochemical, ultrastructural, and molecular findings of Hepatozoon-infected flat-headed cats (Prionailurus planiceps). Vet Clin Pathol. 2008;37:31-41.

55. Salakij C, Sirinarumitr T, Tongthainun D. Molecular characterization of Hepatozoon species in a Leopard Cat (Prionailurus bengalensis) from Thailand. Vet Clin Pathol. 2010;39:199-202

56. Soares HS, Marcili A, Barbieri ARM, Minervino AHH, Moreira TR, Gennari SM, et al. Novel piroplasmid and Hepatozoon organisms infecting the wildlife of two regions of the Brazilian Amazon. Int J Parasitol Parasites Wildl. 2017;6:115-21.

57. Tateno M, Nishio T, Matsuo T, Sakuma M, Nakanishi N, Izawa M, et al. Epidemiological survey of tick-borne protozoal infection in iriomote cats and tsushima leopard cats in Japan. J Vet Med Sci. 2013:75:985-9.

58. Tateno M, Sunahara A, Nakanishi N, Izawa M, Matsuo T, Setoguchi A, et al. Molecular survey of arthropod-borne pathogens in ticks obtained from Japanese wildcats. Ticks Tick Borne Dis. 2015:6:281-9. 
59. Williams BM, Berentsen A, Shock BC, Teixiera M, Dunbar MR, Becker MS, et al. Prevalence and diversity of Babesia, Hepatozoon, Ehrlichia, and Bartonella in wild and domestic carnivores from Zambia, Africa. Parasitol Res. 2014;113:911-8.

60. Kamani J, Harrus S, Nachum-Biala Y, Salant H, Mumcuoglu KY, Baneth G. Pathogenic and endosymbiont apicomplexans in Ctenocephalides felis (Siphonaptera: Pulicidae) from cats in Jerusalem, Israel. Comp Immunol Microbiol Infect Dis. 2018;57:29-33.

61. Lloret A, Addie DD, Boucraut-Baralon C, Egberink H, Frymus T, GruffyddJones T, et al. Hepatozoonosis in cats: ABCD guidelines on prevention and management. J Feline Med Surg. 2015;17:642-4.

62. Maia JP, Harris DJ, Carranza S, Gómez-Díaz E. A comparison of multiple methods for estimating parasitemia of Hemogregarine Hemoparasites (Apicomplexa: Adeleorina) and its application for studying infection in natural populations. PLoS ONE. 2014;9:e95010.

63. Modrý D, Beck R, Hrazdilová K, Baneth G. A review of methods for detection of Hepatozoon infection in carnivores and arthropod vectors. Vector Borne Zoonotic Dis. 2017;17:66-72.

64. Otranto D, Dantas-Torres F, Weigl S, Latrofa MS, Stanneck D, Decaprariis D, et al. Diagnosis of Hepatozoon canis in young dogs by cytology and PCR. Parasit Vectors. 2011;4:55.

65. Ortuño A, Castellà J, Criado-Fornelio A, Buling A, Barba-Carretero JC. Molecular detection of a Hepatozoon species in stray cats from a feline colony in North-eastern, Spain. Vet J. 2008;177:134-5.
66. Hodžić A, Alić A, Beck R, Beck A, Huber D, Otranto D, et al. Hepatozoon martis n. sp. (Adeleorina: Hepatozoidae): Morphological and pathological features of a Hepatozoon species infecting martens (family Mustelidae). Ticks Tick Borne Dis. 2018;9:912-20.

67. Baneth G, Samish M, Alekseev E, Aroch I, Shkap V. Transmission of Hepatozoon canis to dogs by naturally-fed or percutaneously injected Rhipicephalus sanguineus ticks. J Parasitol. 2001;87:606-11.

68. Chomel BB, Kasten RW. Bartonellosis, an increasingly recognized zoonosis. J Appl Microbiol. 2010;109:743-50.

69. Bessas A, Leulmi H, Bitam I, Zaidi S, Ait-Oudhia K, Raoult D, et al. Molecular evidence of vector-borne pathogens in dogs and cats and their ectoparasites in Algiers, Algeria. Comp Immunol Microbiol Infect Dis. 2016:45:23-8.

70. Silaghi C, Knaus M, Rapti D, Kusi I, Shukullari E, Hamel D, et al. Survey of Toxoplasma gondii and Neospora caninum, haemotropic mycoplasmas and other arthropod-borne pathogens in cats from Albania. Parasit Vectors. 2014;7:62.

\section{Publisher's Note}

Springer Nature remains neutral with regard to jurisdictional claims in published maps and institutional affiliations.
Ready to submit your research? Choose BMC and benefit from:

- fast, convenient online submission

- thorough peer review by experienced researchers in your field

- rapid publication on acceptance

- support for research data, including large and complex data types

- gold Open Access which fosters wider collaboration and increased citations

- maximum visibility for your research: over $100 \mathrm{M}$ website views per year

At BMC, research is always in progress.

Learn more biomedcentral.com/submissions 